\title{
Separate Layer Fracturing Technology of Hybrid Fluid on Thick Tight Sandstone Reservoir, Case Study of Huaqing Oil Field
}

\author{
Li Chuan ${ }^{1,2}$, Chen Qiang ${ }^{1,2, ~}$, Zhang Tongwu ${ }^{1,2}$, Yu Xingguo ${ }^{1,2}$, Xian Cheng ${ }^{1,2}$, Xiang Kui ${ }^{1,2}$ \\ ${ }^{1}$ Oil \& Gas Technology Research Institute of Changqing Oilfield Co., Xi'an, China \\ ${ }^{2}$ National Engineering Laboratory for Exploration and Development of Low-Permeability Oil \& Gas Fields, Xi'an, China
}

Email address:

lichuan_cq@petrochina.com.cn (Li Chuan), chengq_cq@petrochina.com.cn (Chen Qiang),

zhangtw1_cq $a$ petrochina.com.cn (Zhang Tongwu), yxg1_cq $a$ petrochina.com.cn (Yu Xingguo),

xianch1_cq $@$ petrochina.com.cn (Xian Cheng), xky1_cq@petrochina.com.cn (Xiang Kui)

${ }^{*}$ Corresponding author

To cite this article:

Li Chuan, Chen Qiang, Zhang Tongwu, Yu Xingguo, Xian Cheng, Xiang Kui. Separate Layer Fracturing Technology of Hybrid Fluid on Thick Tight Sandstone Reservoir, Case Study of Huaqing Oil Field. International Journal of Oil, Gas and Coal Engineering

Vol. 6, No. 5, 2018, pp. 120-125. doi: 10.11648/j.ogce.20180605.17

Received: August 13, 2018; Accepted: August 31, 2018; Published: October 10, 2018

\begin{abstract}
The tight and thick sandstone reservoir, which is represented by Huaqing oilfield, was stimulated by the separated layer fracturing technology in the early period which produces discharge multi-channel between the pay formation and wellbore. For the conventional refracturing technology, the combination of tubing and packers is employed to treat the target layers in sequence. Nevertheless, this conventional technology is confined by the size of the tubing so that the maximum pumping rate can only reach to 3 to $4 \mathrm{~m}^{3} / \mathrm{min}$. It can't meet the requirement of high pumping rate of hybrid fluid SRV fracturing that the treatment effort is not optimum and the stimulation efficiency is very low. In this article, in order to resolve the refracturing problems above for old wells, we introduced a state-of-art downhole releasing separated layer volume fracturing technology and support tools. By applying the releasing tool assembly and exclusive fishing tools, some goals can be easily achieved: to realize the efficient isolation between target layers, to protect the casing while fracturing, to meet the pump rate requirement of SRV fracturing of $11 \mathrm{~m}^{3} / \mathrm{min}$. We deployed the pilot field experiment of Huaqing oilfield and realized the "separated layer multistage SRV fracturing" of tight and thick reservoir. The result shows that the initial production rate of trial wells increases by $2.42 \mathrm{t} / \mathrm{d}$. The field test indicates that this technology presents some advantages such as high pump rate, simple tool assembly, easy operation and low operation risk.
\end{abstract}

Keywords: Releasing Tool, Volume Fracturing, Separate Layer Fracturing Technology, Huaqing Oilfield, Stimulation Effect

\section{Introduction}

Recently, the technologies of unconventional oil and gas field development such as the Bakken high pressure and tight reservoir in North America have evolved rapidly. The combination of 3D seismic, detailed reservoir description, horizontal wells, volume fracturing and diagnosis, factory-like operations, leads to the rapid production increase [1-5]. However, less domestic and foreign research on directional well volume fracturing of separate layer has been done.

Taking the Chang 6 reservoir of Huaqing Oil Field for example, oil reservoir is thick for directional wells and the interlayer develops, which results that the vertical producing degree of hybrid fluid volume fracturing in single layer is not enough. And the conventional fracturing pump rate is relatively low [6]. Hence, in order to increase the stimulated volume and reservoir producing degree, the technique and tools of directional well volume fracturing in separate layer has been developed so that the downhole releasing volume fracturing technology of separate layer was eventually formed. 


\section{Demands of Directional Wells Volume Fracturing for Separate Layers}

The Chang 6 formation of Huaqing Oil Field is an ultra-low permeability reservoir. The sedimentary types of Chang 6 formation is mainly deep and hemi-deep lacustrine facies with sandy debris flow and turbidite flow deposition. The average porosity is $11.12 \%$, and the permeability of core analysis is 0.17 to $0.38 \mathrm{mD}$. The average middle depth of reservoir is $2130 \mathrm{~m}$. The Chang $6_{3}$ reservoir is the main pay formation which is stably distributed. The thickness of sand body is between $30 \mathrm{~m}$ and $50 \mathrm{~m}$, and the effective pay formation thickness is $15 \sim 35 \mathrm{~m}$ on average. The Chang $6_{3}{ }^{1}$ and Chang $6_{3}{ }^{2}$ reservoirs developed by superposition which contain 2 or 3 thin interlayers whose thickness is $0.5 \sim 2.5 \mathrm{~m}$. The reservoir has the feature of high heterogeneity and complex adaptation of oily layer and sand layer.

(1) According to the test of rock mechanics parameters and the calculation of core rock mineral composition, the rock brittleness index of Chang 6 formation in Huaqing Oil Field is $17.7 \% \sim 75.3 \%$; the average value is about $48 \%$. Thus the Chang 6 reservoir is easy to crack.

(2) The image logging result of Chang 6 formation shows that the density of natural fractures is between $0.02 \sim 3.49$ fractures $/ \mathrm{m}, 63.6 \%$ of which is mainly between $0.1-0.5$ fractures $/ \mathrm{m}$. In addition, the analysis result of G-function shows that there are multiple cracks got the feature of filtration, indicating that the natural micro-fractures in the reservoir are widely developed, which is conducive to form complex fracture network [7].

(3) The research has shown that the volume fracturing is more likely to form complex seam network when the maximum horizontal principal stress is relatively as high as the minimum principal horizontal stress [8]. The aeolotropies coefficient of horizontal biaxial stress is less than 0.2 so that the reservoir is easy to form crack network. The rock mechanics parameters have been experimentally determined that the horizontal biaxial stress difference of Chang 6 formation in Huaqing Oil Field is $4 \sim 7 \mathrm{MPa}$, and the aeolotropies coefficient of horizontal biaxial stress is $0.18 \sim 0.21$.

In summary, the natural micro-fractures in Chang 6 formation are widely developed, the rock brittleness index and horizontal biaxial stress difference is moderate, which shows that Chang 6 formation has geological basis for the formation of complex fractures during stimulation. Meanwhile, large-scale volume fracturing is necessary to achieve the goal of "complete transversal stimulation and making full use of the longitudinal direction" [9].

Casing injection fracturing can greatly increase the displacement of the hybrid water fracturing, but only in combined layers. Conventional fracturing on separated layers utilizing tubing injection, the highest displacement rate can only reach $2.4-2.6 \mathrm{~m}^{3} / \mathrm{min}$. Therefore, it is urgent to carry out research on the volume fracturing technology of the directional wells.

\section{Tubing String and Treatment Procedure}

\subsection{Design Concept}

In response to the problems above, downhole releasing volume fracturing technology of separated layers is formed. The technology implements staged fracturing by preset downhole tools, which will greatly increase the treatment displacement rate. Before fracturing, the tool is going down to the design position with tubing, and then the packer has been set and released. During fracturing, the lower layer is fractured by downhole releasing tools. Then the upper layer is fractured by ball-drop and plugging the lower layer with opening sand blast sleeve. Finally, the complete the set of drilling tools are salvaged by entering the special fishing tool. The research of key technology, tools and string performance was carried out.

(1) Downhole releasing tools assembly

The casing in the stimulation section is effectively protected by setting the packer in the upper perforation position. So the multi-segment packing is feasible and large displacement volume fracturing is implemented in stages.

The structure of drilling tool assembly collocation (from bottom to top): ballseat + tubing + Y341-114 packer + constant pressure sliding sleeve + safety joint + Y341-114 packer + Sandblasting sleeve + Y341-114 packer + Y445-114 packer.

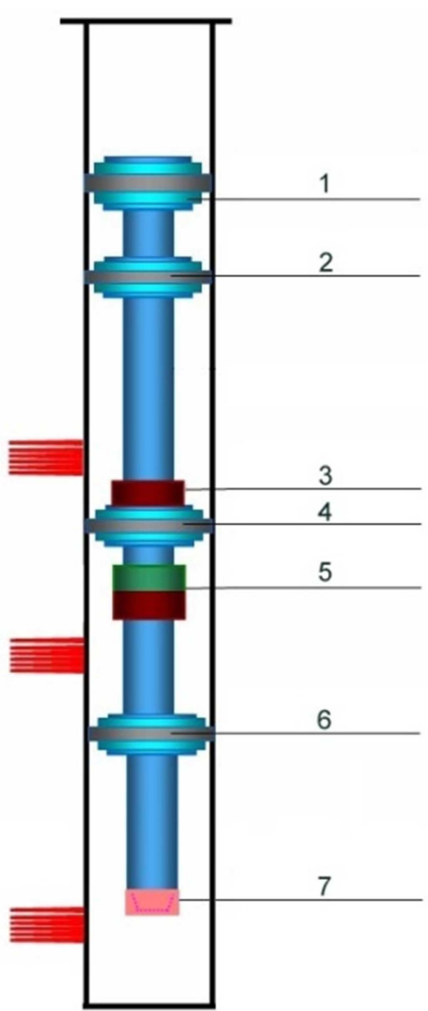

Figure 1. The tool string assembly of downhole releasing volume fracturing in separate laye.r.

1-Y445-144 upper packer; 2 - Y341-144 packer; 3 - sand blasting sliding sleeve; 4 - Y341-144 packer; 5 - constant pressure sliding sleeve + safety joint; 6 - Y341-144 packer; 7- ballseat + choke 
(2) Special fishing tools

Using downhole drilling tools assembly to salvage separately is convenient and safe to operate.
(3) Matching process and technologies were improved, such as well bore pretreatment, sand blasting and salvaging to make sure each process is smoothly carried out.

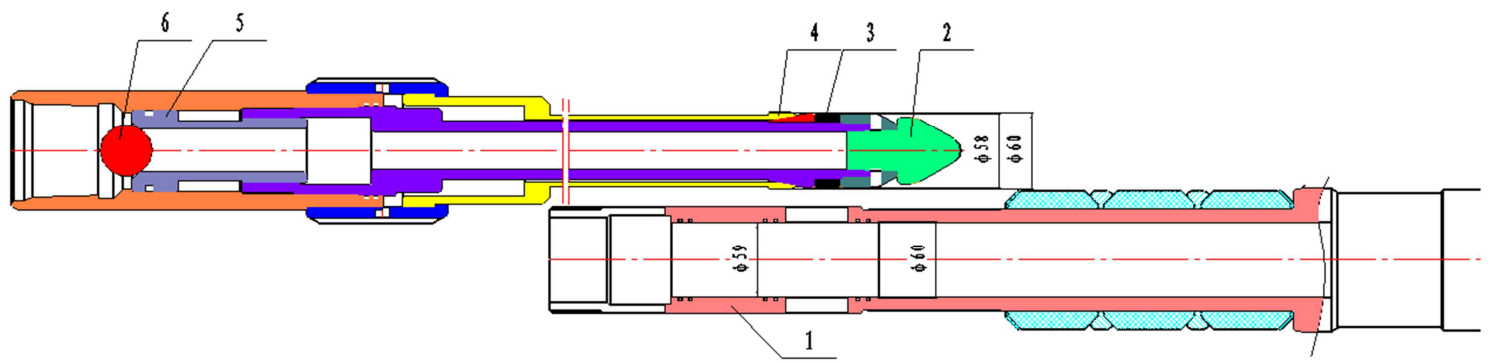

1-Y341 central tube; 2 - lightweight ball; 3 - sealant cylinder; 4 - fishing claw; 5 - releasing sleeve; 6 - balldrop

Figure 2. Y445 bridge plug (special fishing tool).

\subsection{Key Tools}

(1) Y445-114 packer

In order to ensure the packer is always sealed during fracturing, the Y445-114 packer was designed.

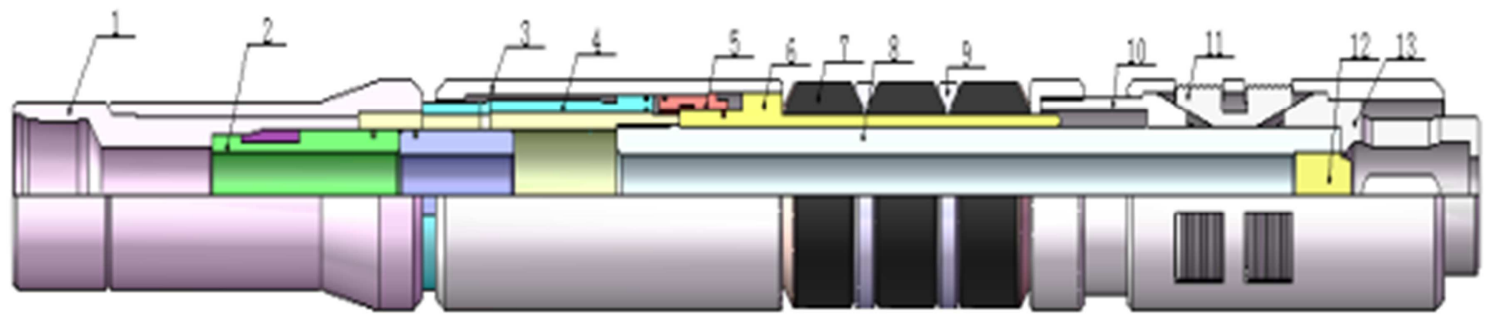

Figure 3. Y445-114 packer structure.

1-upper connector; 2-slide sleeve; 3-upper cylinder liner; 4-lock sleeve; 5- sub piston; 6-rubber shaft; 7-packer 8-central tube;

9-distance ring; 10-upper centrum; 11-slips; 12-seal; 13-lower connector

Working principle: The liquid flows through 1 (upper connector) and enters into the inner cavity of the tool, then enters the 5 (sub piston) by the inlet hole of the 8 (central tube). When the pressure reaches $4 \sim 6 \mathrm{Mpa}$, the shear pin was cut, and the liquid flow pushes 3 (upper cylinder liner), 6 (rubber shaft), 7 (packer), 9 (distance ring), 10 (upper centrum) downward. The lower centrum fixes the anchor of 11 (slips) to the casing wall, then the rubber shaft continues to go down. The sealing process completes till the rubber tube is compressed to deform.

Table 1. The parameter list of Y445-114, Y341-114 packer function.

\begin{tabular}{lll}
\hline Performance & Y445-114packer & Y341-114packer \\
\hline maximum outer diameter $(\mathrm{mm})$ & $\Phi 114$ & $\Phi 114$ \\
minimum inner diameter(mm) & $\Phi 60$ & $\Phi 56$ \\
inner diameter of working sleeve $(\mathrm{mm})$ & $\Phi 121$ & $\Phi 121$ \\
working pressure $(\mathrm{MPa})$ & $\leq 70$ & $\leq 70$ \\
working temperature $\left({ }^{\circ} \mathrm{C}\right)$ & $\leq 120$ & $\leq 120$ \\
length $(\mathrm{mm})$ & 1405 & 1130 \\
sealing pressure(MPa) & 25 & 25 \\
connection type & $2^{7} / 8 \mathrm{UPTBG}$ & $2^{7} / 8 \mathrm{UPTBG}$ \\
release stress $(\mathrm{T})$ & $10-15$ & - \\
unsealed load(T) & $6-8$ & $3-5$ \\
\hline
\end{tabular}

Technical features:

i This technology is suitable to old vertical wells and new wells with separated layers combined with large-scaled hybrid fluid fracturing.

ii The pipe column is designed with a resistance mechanism. So it will not be sealed when it comes across soft or hard resistance tools.

iii The tool has a releasing mechanism. Once the sanding in appears, the stuck tool can be dropped into well for the secondary operations (sand cleanup, salvaging).

iv The tubular packer is equipped with safety joint mechanism to classify the releasing load, which is aim to easily unseal the Y341 packer and reduce the fishing times.

$\mathrm{v}$ The well can be back flushed to ensure the tool is unsealed after the sanding in. 
vi Both ends of the Y341 packer tube are equipped with the two-way constraint slips which can diminish the drilling in deformation of the string.

(2) Sand blasting sleeve

In order to ensure the lower layer is fractured when the upper layer is isolated, and the upper layer can be fractured later. The sand blasting sleeve which is activated by ball-drop is designed. Technical principle: The ball is delivered at 3 (slip sleeve) for sealing and pressure increasing. When the pressure rises to $10 \sim 15 \mathrm{MPa}$, the shearing nails are cut off, 3 (sleeve) goes down to 4 (lower joint). Then the fracturing channel on 1 (upper joint) opens.

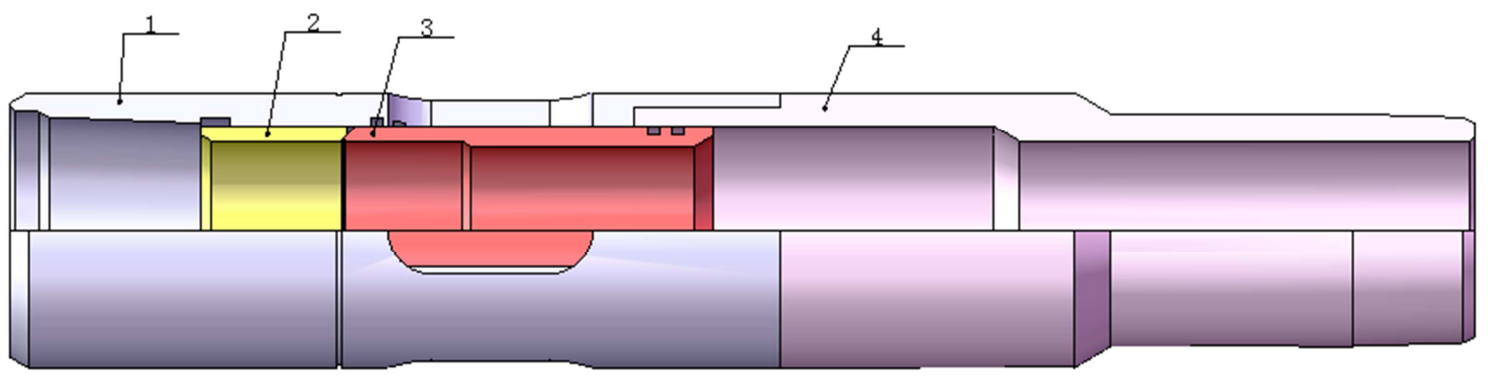

1-upper joint; 2-pressure cap; 3-sleeve; 4-lower joint

Figure 4. Sandblast Sleeve.

Table 2. Technical parameter of sandblast sleeve.

\begin{tabular}{ll}
\hline Parameter & specification of $\mathbf{5}^{\mathbf{1} / \mathbf{2}}$ "casing packer \\
\hline model & HT-93 \\
inner diameter $(\mathrm{mm})$ & $\Phi 121 \sim \Phi 126$ \\
maximum outer diameter $(\mathrm{mm})$ & $\Phi 93$ \\
working temperature $\left({ }^{\circ} \mathrm{C}\right)$ & $\leq 120$ \\
working temperature $(\mathrm{MPa})$ & 70 \\
sleeve opening force $(\mathrm{MPa})$ & $10 \sim 15$ \\
connection type & $27 / 8 \mathrm{UPTBG}$ \\
length $(\mathrm{mm})$ & 500 \\
\hline
\end{tabular}

Technical features:

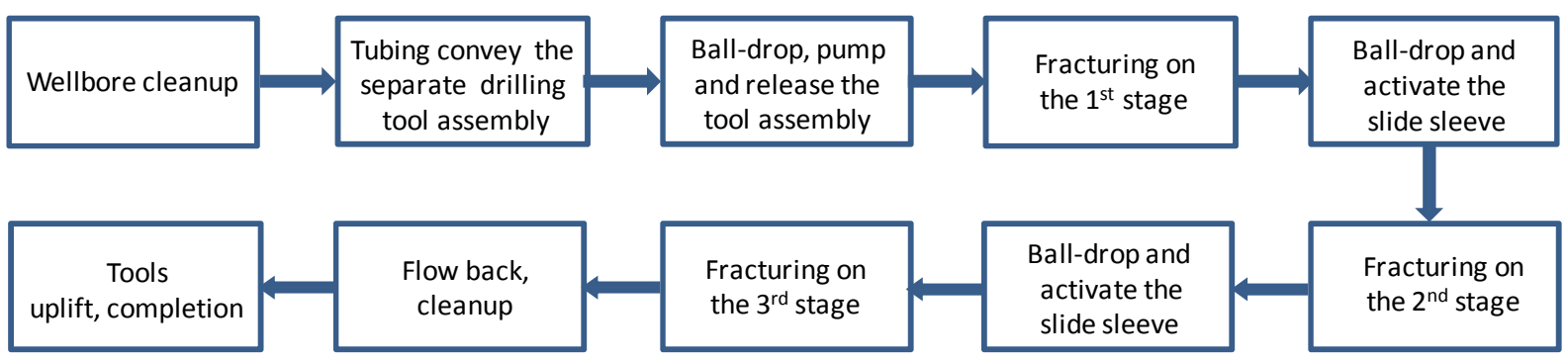

Figure 5. Process flow chart.

(1) The tool tubing is connected after the perforation is completed, the wellbore burr are treated by the scraper.

(2) The drilling tool is gone down in the hole (Figure 1). Then dropping the dissolvable ball, pressurizing the tubing on the surface and sealing the packer.

(3) Go on pressurizing until blowdown. Activate the constant pressure sliding sleeve of the safety joint to open the fracturing channel of the lower layer.

(4) Drop the $35 \mathrm{~mm}$ ball to the upper packer of Y445 and pressurize to release. Hoist the tubing and safety releasing joint.

(5) Fracturing the lower layer.

(6) Drop the $45 \mathrm{~mm}$ resin ball and pressurize the surface pressure. The ball is delivered in place by the small displacement pump rate. Then activate the sliding sleeve of the first packer. The ball falls to the safety joint of the lower sliding sleeve to seal the lower layer. i The sliding sleeve uses special technology for wear-resisting treatment which is to ensure the sand sleeve is not worn out when the amount of sand is increased during stimulation.

ii The fracturing fluid flows widely after the sliding sleeve has been opened.

\subsection{Stimulation Process}

Taking three-layer volume fracturing as an example, the specific construction process is as follows: 
roughness coefficient [10]: $Q=\sqrt{\frac{\pi}{8 \lambda} \cdot \frac{1}{L} \cdot h_{f} D^{5}}$

Where: $\lambda$ is related to Reynolds number and the wall roughness which is dimensionless.

$\mathrm{L}$ is the length of pipeline, $\mathrm{m}$.

$h_{f}$ is the loss of fluid per volume along the path, also named as the loss of pressure along the path, Pa.

$\mathrm{D}$ is the inner diameter of pipe, $\mathrm{m}$.

The diameter of Y445-114 packer is $60 \mathrm{~mm}$ and the Y341-114 packer is $56 \mathrm{~mm}$. The guar gum flowing from casing to packer will appear throttling loss of 2.2MPa. There is also a pressure loss of 1.3-1.9MPa from the fracturing tool through the constant pressure sliding sleeve or the sand blasting sleeve. In the condition of maintaining the constant pressure of stimulation (it is limited by the pressurization performance of casing pipe), the pressure loss will lead to the decrease of $h_{f}$ and displacement rate dropps correspondingly.

According to calculation of the equation, the guar gum base fluid is selected. If it is $5^{1} / 2$ casing, the maximum displacement rate is $11.5 \mathrm{~m}^{3} / \mathrm{min}$ and for $4 \frac{1}{2}$ casing, that is $6.8 \mathrm{~m}^{3} / \mathrm{min}$.

\section{Field Test and Result Analysis}

In May 2018, in order to solve the displacement rate limits of conventional staged fracturing of Chang6 formation in Huaqing field, the separate layer volume fracturing experiment was carried out of selecting typical A1 well with the releasing-style separated layers fracturing technology.

\subsection{Test Well Abstract}

The A1 well is completed with the $5^{1 / 2} 2^{\prime \prime}$ casing and the thickness of pay formation is $30.2 \mathrm{~m}$. The first stimulation adopts 3 stages fracturing separately and testing together. The proppant volume of each layer was $30 \mathrm{~m}^{3}$ and displacement rate was $1.8 \mathrm{~m}^{3} / \mathrm{min}$. The well put into production in December 2013 which produced $3.37 \mathrm{~m}^{3}$ liquid initially and its daily oil production is 1.80 t. The water cut was $36.4 \%$. The dynamic liquid level is $1186 \mathrm{~m}$. The production of the well decreased continuously. By the time of prior to the restimulation, the daily liquid production was $1.33 \mathrm{~m}^{3}$, daily oil production was $1.02 \mathrm{t}$, the water cut was $8.7 \%$, the dynamic liquid level was $1450 \mathrm{~m}$.

\subsection{Experiment Process}

(1) Wellbore treatment: the $\Phi 134 \mathrm{~mm}$ scraper was going down to cleanup the wellbore and the individual section pressure test was validity.

(2) Dropped down the separated drilling tool, sealed the packer and pressurized the tubing. The packers seating was successful at all stages. Continue to pressurize until the pressure suddenly dropping to $6 \mathrm{MPa}$. The constant pressure sliding sleeve activated successfully.

(3) The releasing tool: Drop the $35 \mathrm{~mm}$ ball to the Y445 packer. The pressure dropped suddenly when the pressure was up to $22 \mathrm{MPa}$. The drilling tool released successfully.

(4) The 1st stage fracturing: The site was equipped with 10 units of 2500 model fracturing trucks, 2 sand mixing vehicles, and 1 cement truck. After the pressure test of pipeline and wellhead was validity on the surface, the displacement rate gradually increased to $10.2 \mathrm{~m}^{3} / \mathrm{min}$. The pressure went up to $28.5 \mathrm{MP}$ and then gradually decreased. During the treatment, because the liquid level of the mixer was unstable, there was an empty pump phenomenon and the displacement rate and the pressure fluctuated. After the fourth low-sand ratio slurry pumping ramp was completed, the pumping rate was raised up to $11.2 \mathrm{~m}^{3} / \mathrm{min}$. The pressure went up to 28.6 MPa and then dropped. While the sanding input operation was completed smoothly, the pump off pressure was 15.2MPa (Figure 6). The 1st stage cumulative sand volume was $60 \mathrm{~m}^{3}$. The fluid volume was $611.8 \mathrm{~m}^{3}$.

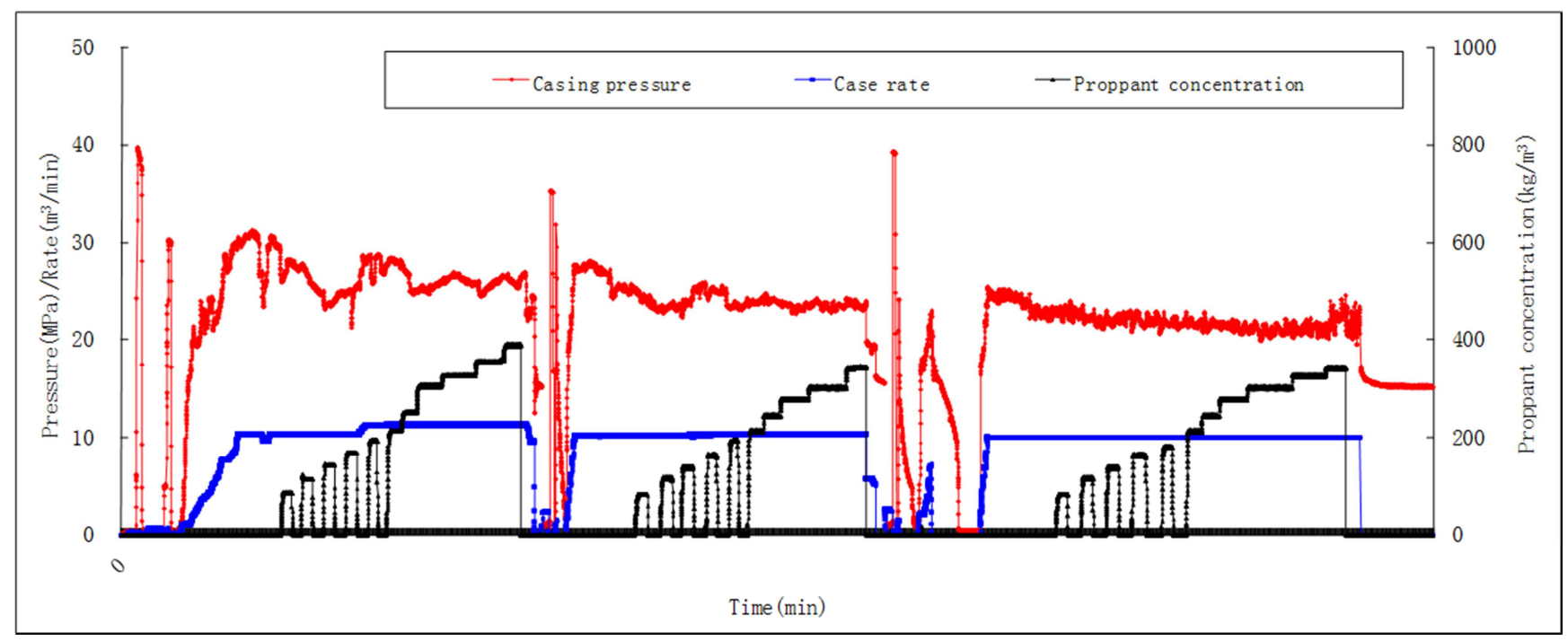

Figure 6. The 1-3 stages fracturing curve of A1 well. 
(5) The ball was dropped to open the No.1 packer with a sliding sleeve to seal the lower layer. After that, the 2nd stage was treated. Pump rate rised up to $10 \mathrm{~m}^{3} / \mathrm{min}$ in a short time. The highest casing pressure was $27.6 \mathrm{MPa}$ and went down gradually. Ramp pressure was about 23.0MPa, and the pump off pressure was $16.0 \mathrm{MPa}$ (Figure 6). The cumulative proppant volume of the 2nd stage was $60 \mathrm{~m}^{3}$. The fluid volume was $629.4 \mathrm{~m}^{3}$.

(6) The ball was dropped to open the No.2 packer with a sliding sleeve to block the lower layer. After that, the 3rd stage was treated. The displacement rate increased to $10.0 \mathrm{~m}^{3} / \mathrm{min}$ in a short time and the pressure decrease gradually when the pressure raised up to $25.0 \mathrm{MPa}$. The treatment pressure was about $21.0 \mathrm{MPa}$, and the pump off pressure was $16.8 \mathrm{MPa}$ (Figure 6). Accumulated sand volume of the $3 \mathrm{rd}$ stage was $60 \mathrm{~m}^{3}$. The fluid volume was $647.0 \mathrm{~m}^{3}$.

(7) Fishing tool: After blowout and sand cleanup, special fishing tools were used to fish the downhole tool.

\subsection{Result Analysis}

This technology achieves the longitudinal three stages separately volume fracturing of dense thick pay layer for the first time. Compared to the conventional technology with the displacement rate of $2-3 \mathrm{~m}^{3} / \mathrm{min}$, this technology can reach the pump rate of $11.2 \mathrm{~m}^{3} / \mathrm{min}$. In this experiment, the accumulative proppant volume is $120 \mathrm{~m}^{3}$ and the fluid volume reached $1259 \mathrm{~m}^{3}$.

The production increased from 1.02tons before the treatment to 3.44tons per day after the stimulation. The daily oil production increment is 2.42 tons. At the moment this paper written, it has stably produced more than 4 months whose cumulative oil increment was 283.8 tons. There is a favorable production increment by this technology.

\section{Conclusions}

The hybrid fluid SRV fracturing with high pump rate is the key technology to efficiently stimulate the tight sandstone reservoir. For the tight and thick sandstone pay formation represented by Huaqing oilfield, the separated layer hybrid fluid volume refracturing technology is demanded. This article introduced the releasing separated layer volume fracturing technology which realizes the efficient isolation between target layers, meantime, the casing can be protected during fracturing operation. This technology presents some advantages such as high pump rate, simple tool assembly, easy operation and low operation risk.

The releasing separated layer volume fracturing technology can serve the separated layer volume fracturing of both vertical wells and old wells. The highlight of this technology is to meet the high pump rate which is the core demand of the stimulation engineers. It is to be noted that for this technology, the prefabricated releasing isolation tools are needed so that there are some necessary pre-works such as scraping the tube, casing pressure test and wellhead pressure test.

\section{References}

[1] Denis Zolnikov, Vladimir Astafyev, Llya Elstov, Nikolay Zavyalov, et al. Massive Hydraulic Fracturing Using Linear Pads in the Achimov reservoirs at the Urengoy Field [R]. SPE 182110-MS, 2016.

[2] Juan Antonio Coronado. Success of Hybrid Fracs in the Basin [R]. SPE 106758, 2007.

[3] ZARGARI S, MOHAGHEGH S D. Field development strategies for bakken shale formation[R]. SPE 139032, 2010

[4] T.T.Palisch, M.C.Vincent, P.J.Handren. Slickwater Fracturing-Food for Thought[R]. SPE 115766, 2008.

[5] Craig Cipolla, Constance Gilbert, Aviral Shama,John, LeBas. Case History of Compltiont Optimization in the Utica [R]. SPE 189838-MS, 2018.

[6] Du Xianfei, Li Jianshan, Qi Yin, et al. Multi-stage fracturing technique in deviated wells of tight thick oil reservoirs [J]. Oil Drilling \& Production Technology, 2012, 34(4): 61-63.

[7] Mullen M, Pitcher J, Hinz D. Does the presence of natural fractures have an impact on production-A case study from the middle Bakken dolomite, North Dakota [R]. SPE 116124, 2010 .

[8] C. Mark Pearson, Larry Griffin, Chris Wright. Breaking up is hard to do: creating hydraulic fracture complexity in the Bakken central basin[R]. SPE 163827, 2013.

[9] MAYERHOFER M J, LOLON E P, WARPINSKI N R, et al. What is Stimulated Reservoir Volume(SRV) [R] SPE 119890, 2008.

[10] Yang Shuren, Wang Zhiming, He Guangyu, et al. Engineering Fluid Mechanics[M]. Beijing:China Petroleum Industry Press, 2006. 